Table 1. The analysis of forced vital capacity (FVC) in KORIL cohort

\begin{tabular}{|c|c|c|c|c|}
\hline & $\begin{array}{l}\text { V1 (enroll- } \\
\text { ment) }\end{array}$ & V2 (1-year) & V3 (2-year) & V4 (3-year) \\
\hline $\mathrm{FVC}(\mathrm{mL}), \operatorname{mean} \pm \mathrm{SD}$ & $\begin{array}{c}2549.5 \pm \\
743.3\end{array}$ & $\begin{array}{c}2479.5 \pm \\
764.4\end{array}$ & $\begin{array}{c}2435.8 \pm \\
742.8\end{array}$ & $\begin{array}{c}2405.7 \pm \\
731.2\end{array}$ \\
\hline FVC $\%$ of predicted, mean \pm SD & $\begin{array}{c}84.70 \pm \\
16.74\end{array}$ & $84.7 \pm 18.1$ & $84.3 \pm 17.6$ & $83.1 \pm 19.1$ \\
\hline Rate of $\mathrm{FVC}$ decline, $\mathrm{mL} \cdot \mathrm{year}^{-1}(95 \% \mathrm{Cl})$ & - & $-14(-49,21)$ & $-62(-104,-21)$ & - \\
\hline $\begin{array}{l}\text { A 10-point decline from V1 in predicted } \\
\text { FVC value, } n(\%)\end{array}$ & - & $10(7.1)$ & $16(13.3)$ & $8(9.4)$ \\
\hline $\begin{array}{l}\text { Relative decline of } 10 \% \text { from } \mathrm{V} 1 \text { in } \\
\text { predicted FVC value, } \mathrm{n}(\%)\end{array}$ & - & $17(12.1)$ & $23(18.9)$ & $17(19.3)$ \\
\hline $\begin{array}{l}\text { Relative decline of } 10 \% \text { from the previous } \\
\text { visit in predicted FVC value, } n(\%)\end{array}$ & - & $17(12.1)$ & $17(14.2)$ & $13(15.3)$ \\
\hline
\end{tabular}

Conclusion: Annually, about $10-15 \%$ of patients experience a relative $\geq 10 \%$ decline from the previous visit in FVC predicted value in RA-ILD.

Acknowledgements: This work was supported by the Korea Health Technology R\&D Project through the Korea Health Industry Development Institute, funded by the Ministry of Health and Welfare, Republic of Korea (grant no.HI14C1277). Disclosure of Interests: None declared

DOI: 10.1136/annrheumdis-2021-eular.2810

\section{POS0556 USEFULNESS OF FDG-PET/CT FOR PREDICTING SPONTANEOUS REGRESSION IN MTX ASSOCIATED LYMPHOPROLIFERATIVE DISORDER WITH RHEUMATOID ARTHRITIS}

T. Kameda ${ }^{1}$, S. Nakashima ${ }^{1}$, H. Shimada ${ }^{1}$, R. Wakiya ${ }^{1}$, M. Mahmoud Fahmy Mansour $^{1}$, M. Kato ${ }^{1}$, K. Sugihara ${ }^{1}$, Y. Ushio ${ }^{1}$, H. Dobashi ${ }^{1} .{ }^{1}$ Kagawa University, Department of Internal Medicine, Division of Haematology, Rheumatology and Respiratory Medicine, Faculty of Medicine, Kita-gun, Japan

Background: Recently, there are many reports from Japan about methotrexate associated lymphoproliferative disorder (MTX-LPD). We are investigating the predictive factor of spontaneous regression (SR) in MTX-LPD. On the other hand, FDG-PET/CT is used for diagnosis of LPD including malignant lymphoma. In addition, it was reported that imaging biomarkers such as metabolic tumor volume (MTV) and total lesion glycolysis (TLG) could predict the prognosis of malignant tumor $(1,2)$. However, there is no report that these imaging biomarkers could predict the SR of MTX-LPD.

Objectives: We investigate the usefulness of FDG-PET/CT for predictive factor of SR in MTX-LPD.

Methods: We enrolled 24 RA patients who diagnosed MTX-LPD and performed FDG-PET/CT from 2005 to 2019. We divided these cases into spontaneous regression cases (SR group; 15 cases) and cases that treated with chemotherapy after MTX discontinuation (CTx group; 9 cases), and compared the difference as follow subjects between two groups; clinical data including histopathological findings, SUVmax to evaluate malignant tumor activity by FDG-PET/CT, MTV and TLG which refer to metabolically active volume of the tumor segmented FDG-PET/CT. In addition, we analyzed cut off levels, sensitivity and specificity using statistical software JMP.

Results: Diffuse large B cell lymphoma (DLBCL) and Hodgkin lymphoma $(H L)$ were 5 and 1 cases in SR group, and 1 and 5 cases in CTx group. In addition, MTV and TLG by FDG-PET/CT was significantly lower in SR group, although SUVmax is no difference between two groups (figure 1). Cut off levels of MTV and TLG were $103.12 \mathrm{ml}$ (sensitivity; $88.9 \%$, specificity; $86.7 \%$ ) and $361.75 \mathrm{ml}$ (sensitivity; $88.9 \%$, specificity; $86.7 \%$ ), respectively.

Conclusion: We suggested that MTV and TLG were useful for predict of SR in MTX-LPD.

REFERENCES:

[1] Chen HH, Chiu NT, Su WC. et al. Prognostic value of whole-body total lesion glycolysis at pretreatment FDG PET/CT in non-small cell lung cancer. Radiology. 2012 Aug;264(2):559-66

[2] Chu KP, Murphy JD, La TH. et al. Prognostic value of metabolic tumor volume and velocity in predicting head-and-neck cancer outcomes. Int J Radiat Oncol Biol Phys. 2012 Aug 1;83(5):1521-7.
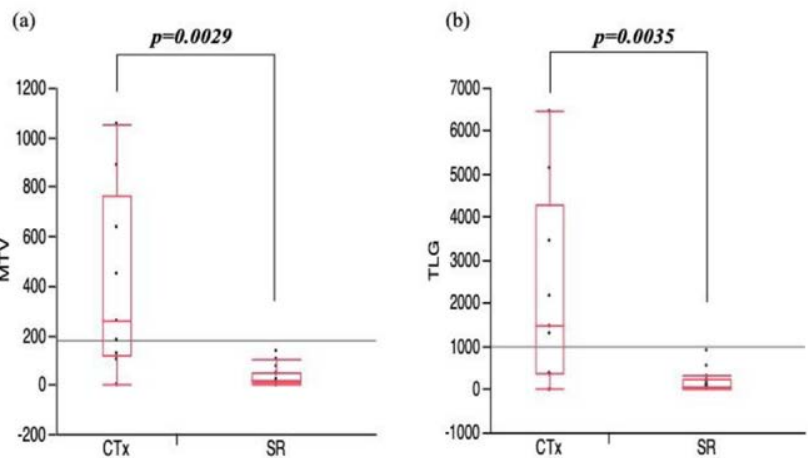

Figure 1. Comparison of the level of MTV(a) and TLG (b).

Disclosure of Interests: None declared

DOI: 10.1136/annrheumdis-2021-eular.2812

\section{POS0557 1 THE RELATION BETWEEN INVOLVEMENT OF INDIVIDUAL JOINTS OF THE UPPER EXTREMITY AND GRIP FORCE IN EARLY RHEUMATOID ARTHRITIS}

M. Rydholm ${ }^{1,2}$, A. Sharma ${ }^{2}$, I. Wikström ${ }^{1,2}$, L. T. H. Jacobsson ${ }^{2,3}, \underline{\text { C. Turesson }}{ }^{1,2}$ ${ }^{1}$ Skåne University Hospital, Department of Rheumatology, Malmö, Sweden;

${ }^{2}$ Lund University, Rheumatology, Department of Clinical Sciences, Malmö, Malmö, Sweden; ${ }^{3}$ Gothenburg University, Department of Rheumatology and Inflammation Research, Sahlgrenska Academy, Gothenburg, Sweden

Background: Rheumatoid arthritis (RA) has a major impact on hand function in many patients.

Objectives: The objective of this study was to investigate the relation between swelling and tenderness of individual joints in the upper extremities and grip force in patients with early RA.

Methods: An inception cohort of patients with early RA (symptom duration $\leq 12$ months), recruited in 1995-2005, was investigated and followed in a structured program. All patients were examined by the same rheumatologist according to a structured protocol, and swelling and tenderness of individual joints was recorded. Grip force (Newton, N) was measured using the electronic instrument Grippit (AB Detektor, Gothenburg, Sweden). Average grip force values of each hand were evaluated and compared to the expected, based on age- and sex-specific reference values from the literature (1). Grip force was expressed as \% of expected values. Linear regression analyses were used to assess the relation between upper extremity joint involvement in individual joints and grip force, using the presence/absence of synovitis/ tenderness in each joint as covariates. For the multivariate analysis, covariates with $p<0.10$ in the univariate analyses were selected. In cases with major collinearity (Spearman's $r>0.3$ ), the covariate with the stronger association in the univariate analysis was included.

Results: A total of 215 patients with early RA (71\% women; mean age 60 years) were investigated. The median symptom duration at inclusion was 7 months; interquartile range 5-10. The median 28 joint counts for swollen joints was 7 (interquartile range, IQR 5-11) and for tender joints 4 (IQR 1-9). In univariate analyses, swelling of the wrist, each metacarpophalangeal (MCP) joint and proximal interphalangeal (PIP) joints III and V, as well as tenderness of the elbow, wrist and each MCP and PIP joint were associated with significantly reduced grip force in the right hand. In the left extremity, corresponding associations were observed for swelling of the wrist, each MCP joint and PIP joints I and V, and for tenderness of the wrist and each MCP and PIP joint. In multivariate analysis, wrist synovitis was associated with reduced grip force ( $\beta-11.0$ and $-14.3 \%$ of expected, respectively). There were also independent significant associations for tenderness of MCP IV and the elbow with reduced grip force in the right hand, and for swelling of MCP I and MCP V with reduced grip force in the left hand (Table 1). 
Table 1. Joint involvement associated with average grip force ( $\%$ of expected value), multivariate linear regression

\begin{tabular}{lcc}
\hline & Unstandardized $\beta$ & $95 \% \mathrm{Cl}$ \\
\hline Right hand & & \\
Swollen Wrist & -11.0 & -17.5 to -4.5 \\
Tender MCP IV & -15.6 & -25.2 to -6.0 \\
Tender PIP V & -2.3 & -12.0 to 7.3 \\
Tender Elbow & -11.7 & -22.1 to -1.3 \\
Left hand & -14.3 & -20.4 to -7.6 \\
Swollen Wrist & -7.6 & -14.6 to -0.6 \\
Swollen MCP I & -11.7 & -21.9 to -1.5 \\
Swollen MCP V & -0.8 & -9.2 to 7.5 \\
Swollen PIP I &
\end{tabular}

MCP: Metacarpo phalangeal jointPIP: Proximal interphalangeal joint

Conclusion: Involvement of several different joints in the upper extremity contributes to impaired hand function. Clinical synovitis of the wrist was associated with reduced grip force in both hands. In the left hand, arthritis of the thumb had a major impact on grip force. In general, MCP involvement was found to be more important for the grip than PIP involvement.

REFERENCES:

[1] Nilsen T et al. Scand J Occup Ther 2012; 19: 288-96

Disclosure of Interests: None declared

DOI: 10.1136/annrheumdis-2021-eular.2837

\section{\begin{tabular}{|l|l}
\hline POS0558 & STATE OF ADIPOCYTOKINES IN PATIENTS WITH
\end{tabular} RHEUMATOID ARTHRITIS WITH SUBCLINICAL ATHEROSCLEROSIS}

I. Krivotulova ${ }^{1}$, T. Chernysheva ${ }^{1} .{ }^{1}$ Orenburg State Medical University (OrSMU), Department of Internal Diseases, Orenburg, Russian Federation

Background: The causes of accelerated atherosclerosis in rheumatoid arthritis (RA) are not completely understood [1]. Therefore, there is a need to identify new biomarkers of increased cardiovascular risk in RA.

Objectives: To establish the relationship of adipocytokines (adiponectin and leptin) with metabolic and inflammatory markers of subclinical atherosclerosis in RA patients.

Methods: The study included 88 women with RA according to the ACR (American College of Rheumatology)/EULAR (European League Against Rheumatism) criteria, 2010 [2] who visited the adaptation therapy clinic of Orenburg State Medical University. The mean $\pm S D$ age was $46.43 \pm 8.5$ years and the mean $\pm S D$ disease duration was $8.21 \pm 5.56$ years.

We evaluated the following laboratory parameters in all patients: erythrocyte sedimentation rate (ESR), total cholesterol, triglycerides (TAG), high-density lipoproteins (HDL), low-density lipoproteins (LDL) and C-reactive protein (CRP). Serum concentrations of adiponectin, leptin, rheumatoid factor (RF), tumor necrosis factor- $\alpha$ (TNF- $\alpha$ ), and interleukin-17 (IL-17) were determined by enzyme-linked immunosorbent assay (ELISA)

We carried out ultrasound (US) duplex scanning of the carotid arteries by the device "Philips Epiq 7" with linear transducer with frequency of 4-18 $\mathrm{MHz}$ with the division into 2 groups of patients: group I consisted of 44 women with US signs of subclinical atherosclerosis, group II -44 women without these signs. The control group included 30 women without inflammatory joint diseases and US signs of subclinical atherosclerosis and similar in gender, age and body mass index (BMI) to RA patients.

The program STATISTICA, 12.0 was used for statistical analysis.

Results: The serum adiponectin level was significantly higher in RA patients compared to the control group ( $p<0.0001$ ): $40.88 \pm 13.60 \mathrm{ng} / \mathrm{ml}$ versus $22.75 \pm 11.27 \mathrm{ng} /$ $\mathrm{ml}$. The level of leptin in the blood serum of women with RA and healthy individuals was approximately the same and amounted to $18.07 \pm 14.02 \mathrm{ng} / \mathrm{ml}$ and $16.60 \pm 11.45 \mathrm{ng} / \mathrm{ml}$ respectively. When comparing the levels of adipocytokines in RA patients, the predominance of concentrations of both adipokines in patients with paraclinical atherosclerosis were noted. The adiponectin concentration was $46.08 \pm 14.44 \mathrm{ng} / \mathrm{ml}$ versus $35.70 \pm 10.51 \mathrm{ng} / \mathrm{ml}(p<0.001)$. The leptin level was $26.40 \pm 20.06 \mathrm{ng} / \mathrm{ml}$ versus $14.96 \pm 16.62 \mathrm{ng} / \mathrm{ml}(\mathrm{p}<0.01)$.

Correlation analysis showed an negative relationship between adiponectin levels and metabolic markers of atherosclerosis: $B M I(r=-0.52 ; p<0.05)$, neck circumference (NC) $(r=-0.50 ; p<0.05)$, levels of LDL $(r=-0.77 ; p<0.001)$ and TAG $(r=-0.59$; $p<0.05)$ as well as proinflammatory cytokines: TNF- $\alpha(r=-0,48 ; p<0.05), I L-17(r=$ $-0.60 ; p<0.01)$ in patients of both groups. The increase in adiponectin concentration in group II patients was associated with the duration of administration of methotrexate $(r=0.49 ; p<0.05)$ and glucocorticosteroids $(r=0.71 ; p<0.001)$. Direct correlations were found between the level of leptin and BMI $(r=0.48 ; p<0.05), N C$ $(r=0.48 ; p<0.05)$, LDL $(r=0.54 ; p<0.05)$ and TAG $(r=0.45 ; p<0.05)$, CRP $(r=0.49$; $\mathrm{p}<0.05)$ and IL-17 ( $\mathrm{r}=0.52 ; \mathrm{p}<0.05)$ in group I patients.

Conclusion: There is a significant increase in the production of adipocytokines in RA with subclinical atherosclerosis. Correlations of levels of adipokines with metabolic and inflammatory markers of atherosclerosis, on the one hand, indicate the influence of adipose tissue on systemic inflammation and, on the other hand, confirm the involvement of proinflammatory cytokines in the development of atherosclerotic vascular damage in patients with RA.

\section{REFERENCES:}

[1] Mahmoudi M, Aslani S, Fadaei R, Jamshidi AR. New insights to the mechanisms underlying atherosclerosis in rheumatoid arthritis. Int $\mathrm{J}$ Rheum Dis. 2017;20(3):287-297. doi: 10.1111/1756-185X.12999

[2] Aletaha D, Neogi T, Silman AJ, et al. 2010 Rheumatoid arthritis classification criteria: an American College of Rheumatology/European League Against Rheumatism collaborative initiative. Ann Rheum Dis. 2010;69:1580-8. doi:10.1136/ard.2010.138461

Disclosure of Interests: None declared

DOI: 10.1136/annrheumdis-2021-eular.2853

\section{POS0559 \\ SPECKLE TRACKING BETTER DETECTS SUBCLINICAL MYOCARDIAL DYSFUNCTION IN PATIENTS WITH RHEUMATOID ARTHRITIS}

I. Kirillova ${ }^{1}$, T. Popkova ${ }^{1}$, Y. Gorbunova ${ }^{1}$, A. Volkov' ${ }^{1}$, E. Nasonov ${ }^{1} .{ }^{1}$ V.A. Nasonova Research Institute of Rheumatology, Laboratory of Systemic Rheumatic Diseases, Moscow, Russian Federation

Background: The risk of developing cardiovascular complications and death in rheumatoid arthritis (RA) is $50 \%$ higher than in the total population. These clinical events depend from risk factors for cardiovascular diseases, chronic inflammation and inflammatory myocardial infiltration. A new method for detecting early myocardial dysfunction is echocardiography using speckle tracking echocardiography. Objectives: to determine the frequency of myocardial dysfunction (lower global longitudinal epicardial strain of left ventrical (LV), diastolic dysfunction of left ventricle (LVDD)) using standard and novel echocardiographic methods in patients (pts) with RA prior to therapy with bDMARDs, examine its relationship with markers of inflammation.

Methods: a total of 28 pts with a valid diagnosis of RA (ACR/EULAR, 2010): 23 $f(82 \%) / 5 \mathrm{~m}(18 \%)$ were included, median $(\mathrm{Me})$ age - 56 [interquartile range (IR) 34;65] years, Me RA duration-14,5 [IR 7;87] months; all pts with RA demonstrated a high disease activity (Me DAS28 6.06, [IR 5,4;6,6]), seropositive for $\operatorname{lgM}$ RF $(88 \%)$ and/or ACCP (84\%) without any experience of administration of bDMARDs. The control group consisted of 10 healthy subjects, which were matched by sex and age. All pts were assessed for traditional risk factors for cardiovascular disease (ESC guidelines, 2011), echocardiography, tissue Doppler imaging, and the speckle tracking assessment of left ventricle longitudinal strain DD was allocated according to the ESC guidelines for the diagnosis and treatment of heart failure (2018). Arterial hypertension was detected in 5 pts with RA Results: In pts with RA LVDD was more often detected ( $8(31 \%)$ vs $0 \%, p=0.05)$ than in controls. The values of E LV $(0.77$ [0.62;0.94] ms vs 1.25 [1.03;1.51] ms $\mathrm{p}=0.0001$ ) were lower than in control group. Speckle-tracking method detected lower global longitudinal epicardial strain $(-16.5[-18.9 ;-13.6] \%$ vs $-21.58[-22.1$; $20.4] \%, p=0.0001) .17(61 \%)$ RA pts showed a decrease global longitudinal epicardial strain. There were no between-group differences in left ventricular ejection fraction, LV sizes, LV myocardial mass index in RA pts with controls. There were correlations between the global longitudinal epicardial strain and DAS28 $(r=0,9$ $p<0,02)$, tender joint score $(r=0,6, p<0,02)$, radiological stage $(r=0,6, p<0,008)$ the presence of systemic manifestations $(r=0,5, p<0,03)$.

Conclusion: In pts with RA frequently $(61 \%)$ were detected lower global longitudinal epicardial strain, which are associated with a high activity of the inflammatory process. Speckle-tracking echocardiography is better at detecting early myocardial dysfunction than tissue Doppler.

Disclosure of Interests: None declared

DOI: 10.1136/annrheumdis-2021-eular.2870

\section{POS0560 \\ CO-MORBIDITIES MAY NOT CHANGE TREATMENT CHARACTERISTICS OF THE RHEUMATOID ARTHRITIS PATIENTS}

M. E. Tezcan ${ }^{1}$, G. Geçmez ${ }^{2}$, Ö. Volkan ${ }^{1}$, N. Şen ${ }^{1}$, S. Yilmaz-Oner ${ }^{1} .{ }^{1}$ Kartal Dr. Lütfi Kırdar Şehir Hastanesi, Rheumatology, İstanbul, Turkey; ${ }^{2}$ Kartal Dr. Lütfi Kırdar Şehir Hastanesi, Internal Medicine, Istanbul, Turkey

Background: Several co-morbidities may usually accompany rheumatoid arthritis (RA)(1). These can have direct or indirect implications for the severity of rheumatoid arthritis, the doctors' decision of disease-modifying treatment, and the functional disability of RA patients.

Objectives: It has been previously shown that various co-morbidities can have negative effects on the functional status, quality of life and life expectancy of RA patients individually (2). Here, we evaluated the effect of weight of all co-mor bidities on treatment of RA patients and functional disability. Our hypothesis "The functional status of RA patients with moderate and severe co-morbidities is impaired compared to patients with mild co-morbidities, and the treatment characteristics of RA are different between these groups". 